\title{
Designing and Evaluation of Functional Modest Designs of Women Bath Wear
}

\author{
Shanu Parashar and Meenu Srivastava* \\ Department of Textiles and Apparel Designing, College of Community and \\ Applied Sciences, MPUAT, Udaipur, Rajasthan, India \\ *Corresponding author
}

\section{A B S T R A C T}

\section{Keywords}

Modesty, Outfits, Design, Features, Evaluation

Article Info

Accepted: 17 October 2020 Available Online: 10 November 2020
The present paper is an outcome of the research conducted to design modest bath wear outfits for women, based on their clothing needs identified in preliminary survey to make modest and comfortable dressing for them. The researcher creatively designed 30 different sketches of dresses giving functionality and modesty features prime importance. These designs were critically evaluated by expert panel on selected parameters using five-point continuum scale. Findings revealed that the developed functional designs of modest bath wear for women were found highly acceptable in terms of aesthetic, functional and constructional attributes by the panel members.

\section{Introduction}

Modesty dictates the proper way to cover the body for social acceptance. It is the covering of a person's body according to the code of decency according to societal norms. Standards of modesty differ among various cultures and situations, and they change over time. Standards of decency are molded by cultures and social systems. Each society has its own accepted standards of modesty. ${ }^{1}$ Guarding against the temptations that are believed to result from improper dress, particularly of women, is a major motivation for rendering modesty one of the highest virtues in this tradition. ${ }^{2}$
In general Indian clothing is more than just a means to cover up their modesty. It is a part of their cultural and religious identity, social status, and personal style statement. ${ }^{3}$

Today, clothing has become mainly a "statement" of position, a way to allure, or an attempt to fit in. Clothing has two main purposes: to cover the shame of sin, and to glorify God. Those purposes are becoming lost the collective conscience even while retaining them has become increasingly more important in this age of immodesty and materialism. Modest clothing essentially relates to having a degree of awareness when it comes to covering up of the body. The 
decision can be due to religio- ethnic fulfillment or to attain a certain asthetic and level of ease because it is not just a trend that's tried to spirituality. ${ }^{4}$ Modest bath wear is the need of the hour for Indian women having religious mindset and fun-loving attitude of exploring nature. Modest bath wear outfits are produced for sustaining one's modesty.

Taking holy bath is one of the important ritual in Hindu culture, but at the same time wearing appropriate bath wear outfit is also a major concern among Indian females at communal places. Most of the pilgrims interviewed at the time of data collection reported lack of comfort in present outfit worn by them during taking holy bath. Problems related to material used in garment such as fibre content, texture, drape and compactness of weave, structural design of the dress and also with the constructional features were highlighted by the respondents. ${ }^{5}$

Based on the findings of the preliminary research conducted to identify the functional clothing need of women in taking holy bath at communal places, the present research work on "Designing and evaluation of functional modest designs of women bath wear" was conducted to with the objective to develop functional designs of modest bath wear for women and its evaluation.

\section{Materials and Methods}

The present study was carried out in the department of Textiles and Apparel Designing, College of Community and Applied Sciences, MPUAT, Udaipur, Rajasthan. The study was based on experimental research design and involved developing functional modest bath wear clothing designs for women. The researcher also developed a proforma for evaluation of developed designs on selected parameters of aesthetic, functional and constructional attributes based on five-point rating scale. The evaluation proforma was used by expert panel to judge the suitability of the modest bath wear designs. The responses derived were coded and presented in table 1 .

\section{Results and Discussion}

\section{Designing of functional bath wear outfits}

The researcher developed designs of modest bath wear outfits keeping in mind required functional features and structural parameters of selected textiles with foremost focus to provide modesty in developed clothing designs. The designs of upper clothing were made which can be used with any routine wear lower garment like, ghagra/lehngra/salwar, etc. Loose fitting garments provide more modesty than garments that are worn close to the skin and also more comfortable to wear. Researcher made lots of effort to sketch thirty free hand designs of short kurtis on paper. The styling features were kept different for every design. Maximum body coverage was given prime importance in view of the need of modesty during bathing besides considerations of functionality, aesthetic and comfort features.

\section{Evaluation of functional bath wear outfits}

The developed thirty designs of modest bath wear outfits along with their specifications were shown to expert panel for evaluation using developed proforma having various parameters. The scores obtained were compiled and mean score was calculated to give ranks to all the developed designs.

Plate-1 depicts the top ten functional designs of modest bath wear outfits for women along with their specifications. Design code 1, 2, 4, $10,13,17,19,20,21$ and 30 were found most appealing, modest and good functionality by the judges. 
Table.1 Mean score and ranking of the developed functional modest bath wear outfit design

\begin{tabular}{|c|c|c|c|c|c|}
\hline \multirow{2}{*}{$\begin{array}{l}\text { Design code } \\
\text { number }\end{array}$} & \multicolumn{3}{|c|}{ Parameters (mean) } & \multirow[t]{2}{*}{ Mean score } & \multirow[t]{2}{*}{ Rank } \\
\hline & Aesthetic & Functional & Constructional & & \\
\hline 1. & 4.3 & 4.7 & 4.3 & 13.3 & II \\
\hline 2. & 4.7 & 4.1 & 4.4 & 13.2 & III \\
\hline 3. & 3.2 & 4.3 & 4.2 & 11.7 & XVI \\
\hline 4. & 3.9 & 4.5 & 4 & 12.4 & $\mathrm{X}$ \\
\hline 5. & 3.4 & 4.2 & 4.1 & 11.7 & XVI \\
\hline 6. & 3.9 & 4.3 & 4 & 12.2 & XII \\
\hline 7. & 3.1 & 3.3 & 4.1 & 10.5 & $\mathrm{XXV}$ \\
\hline 8. & 4.1 & 4.1 & 3 & 11.2 & XIX \\
\hline 9. & 3.4 & 3.4 & 3.3 & 10.1 & XXVIII \\
\hline 10. & 4.8 & 4.9 & 4.7 & 14.4 & I \\
\hline 11. & 3.2 & 4.2 & 3.3 & 10.7 & XXIV \\
\hline 12. & 4 & 4.3 & 4 & 12.3 & XI \\
\hline 13. & 4.5 & 4.5 & 3.9 & 12.9 & VI \\
\hline 14. & 3.6 & 4.1 & 4.1 & 11.8 & $\mathrm{XV}$ \\
\hline 15. & 3 & 4.1 & 4.1 & 11.2 & XIX \\
\hline 16. & 4 & 3.1 & 3.2 & 10.3 & XVII \\
\hline 17. & 4.5 & 3.9 & 4.4 & 12.8 & VII \\
\hline 18. & 4 & 4 & 3 & 11 & XXII \\
\hline 19. & 4.3 & 4.6 & 4.1 & 13 & $\mathrm{~V}$ \\
\hline 20. & 3.8 & 4.5 & 4.2 & 12.5 & IX \\
\hline 21. & 4.3 & 4.7 & 4.1 & 13.1 & IV \\
\hline 22. & 3.7 & 4.3 & 3.9 & 11.9 & XIV \\
\hline 23. & 3.4 & 3.3 & 3.4 & 10.1 & XXVIII \\
\hline 24. & 3.2 & 3.1 & 4.2 & 10.5 & XXV \\
\hline 25. & 3.2 & 4.2 & 4.1 & 11.5 & XVIII \\
\hline 26. & 3.4 & 3.3 & 3.4 & 10.1 & XXVIII \\
\hline 27. & 3.3 & 4.2 & 3.4 & 10.9 & XXIII \\
\hline 28. & 4 & 4 & 3.1 & 11.1 & XXI \\
\hline 29. & 3.8 & 4.3 & 4.1 & 12.2 & XII \\
\hline 30. & 4.4 & 4.5 & 4 & 12.7 & VIII \\
\hline
\end{tabular}


Plate.1 Specification sheet of top ten functional modest bath wear outfit design

\begin{tabular}{|c|c|c|}
\hline S.No & Designs & Descriptions \\
\hline 1. & & $\begin{array}{l}\text { Design number 1is a modified double layer poncho with boat } \\
\text { neckline. It has elasticated arm holes to make it easy to wear } \\
\text { besides retaining it in place when worn. It has to be used with } \\
\text { an 'Inner clothing', which also has boat neck and half sized } \\
\text { raglan sleeves to increase modesty as well as comfort to } \\
\text { prevent hindrance in body movements. Inner clothing is } \\
\text { having front opening with large sized loops and buttons so } \\
\text { that it will be easy to open in wet condition. }\end{array}$ \\
\hline 2. & & $\begin{array}{l}\text { Design number } 2 \text { is having a sleeveless jacket to give modesty } \\
\text { to the garment by appropriately covering the chest area with } \\
\text { its loose-fitting design. It has opening on both shoulders and } \\
\text { fastens with one large sized button on both sides so that it will } \\
\text { be easy to put on and takeoff. Inner has a short round neck } \\
\text { three fourth flared sleeves. }\end{array}$ \\
\hline 4. & & $\begin{array}{l}\text { Design number } 4 \text { is having one layered upper fabric which is } \\
\text { attached around neck edge and it is full of gathers for giving } \\
\text { fullness on upper body area therefore it will be appear modest. } \\
\text { Inner portion having kimono sleeves and front opening with } \\
\text { big size press buttons to facilitate trouble-free change of } \\
\text { clothing in wet condition. }\end{array}$ \\
\hline 10. & & $\begin{array}{l}\text { Design number } \mathbf{1 0} \text { is a kind of wrap around which overlaps } \\
\text { and is tied to the left waist side of the garment. The design has } \\
\text { fine knife pleats on both the shoulders at neckline for } \\
\text { functionality purpose. Lower part of the garment is a bias cut } \\
\text { skirt for creating flared effect so that it will not cling to the } \\
\text { body. It has kimono sleeves. Because of wrap around pattern, } \\
\text { it is very comfortable to change after use. }\end{array}$ \\
\hline
\end{tabular}




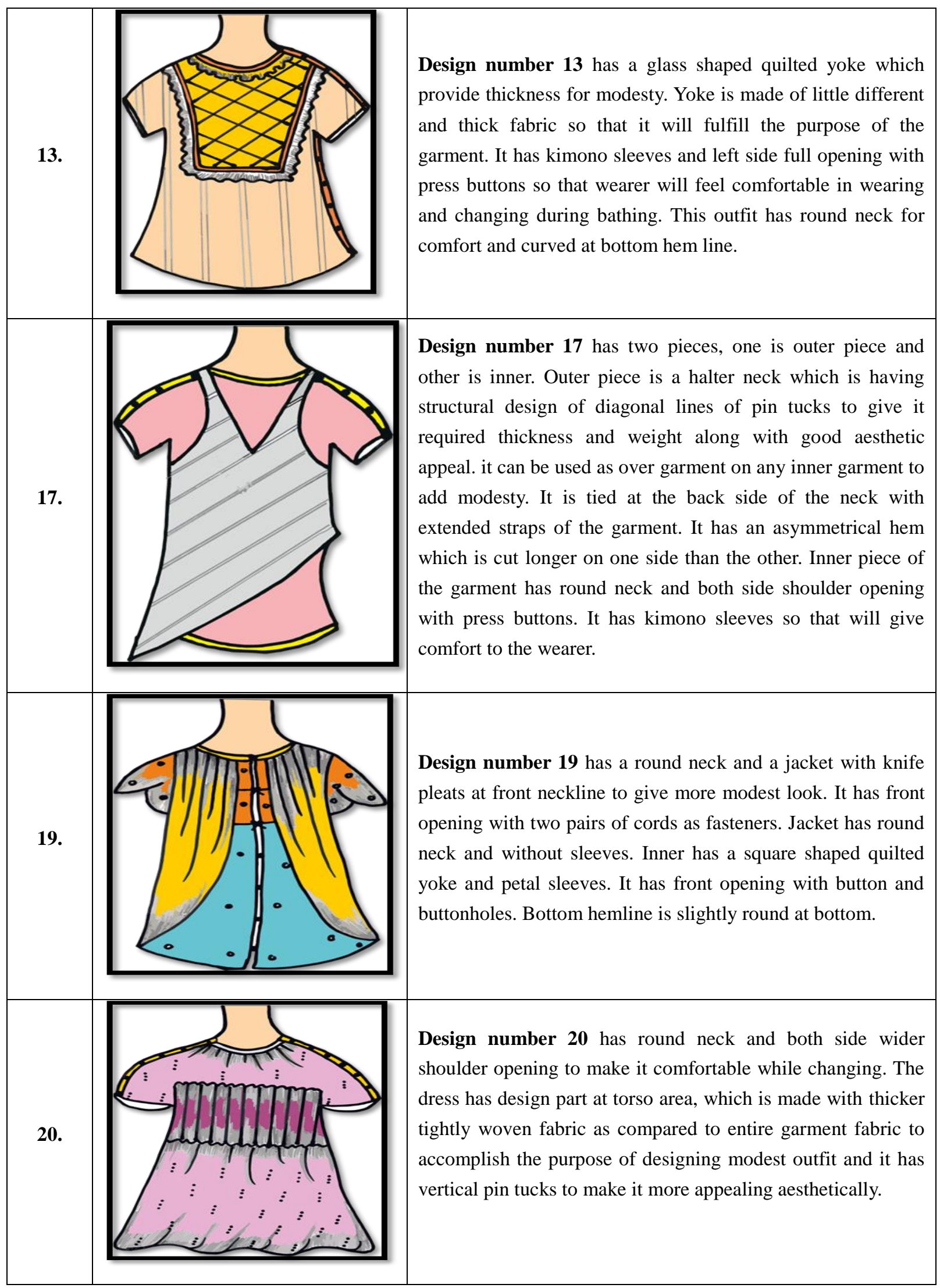




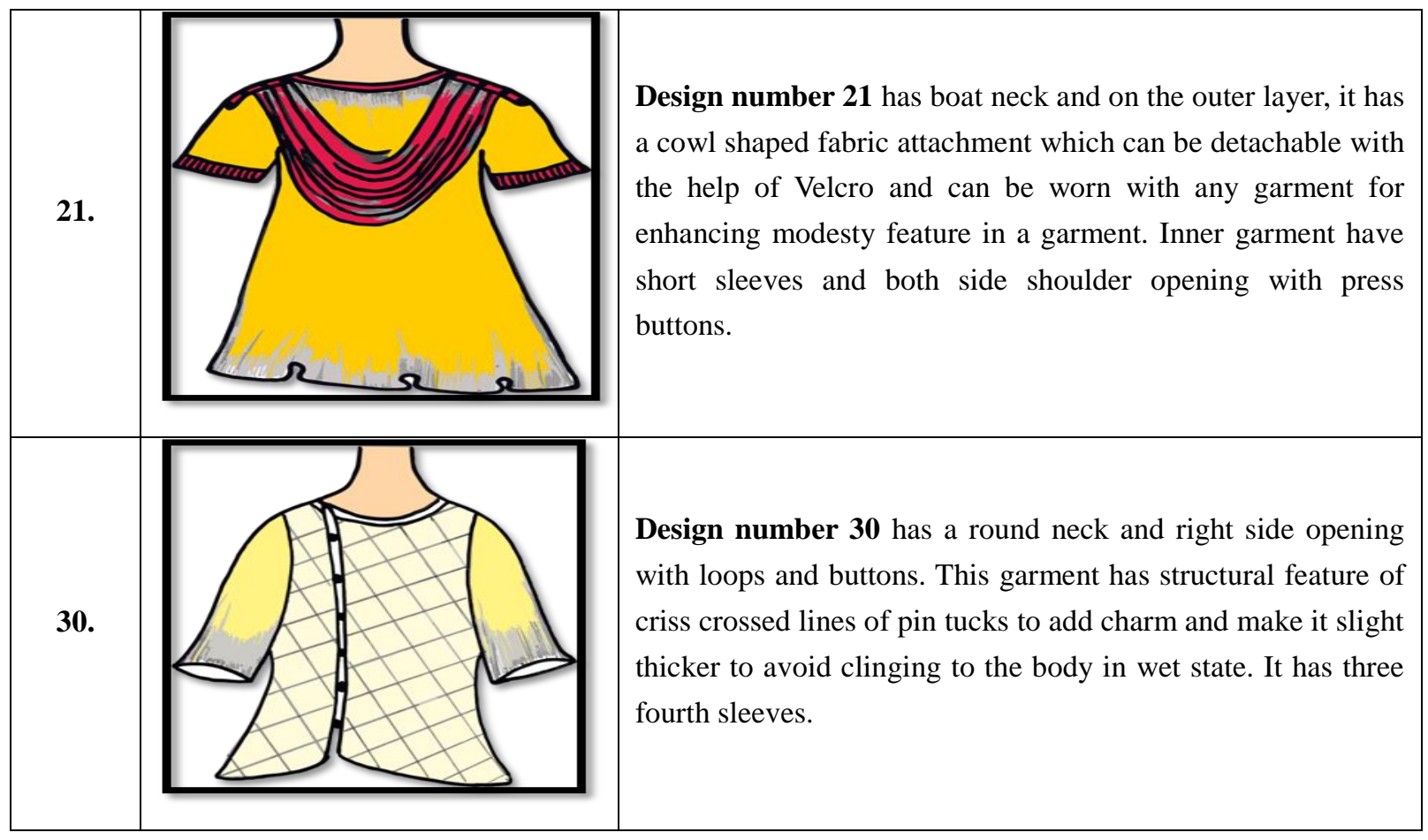

Table-1 presents the mean scores of all the thirty designs on different parameters along with their respective ranks.

Data in table-1 portrays clearly that the developed thirty designs by the researcher were reported to have a mean score in the range of 10.1 to 14.4 . All the designs were found very innovative, creative and functionally appropriate as depicted from the mean scores obtained.

It can be seen that design number 10 got I rank with the mean score of 14.4 , design code number 1 got II rank with the 13.3 mean score, design number 2 stand for rank III and its mean score is 13.2, design number 21 got rank IV by the 31.1 mean score, design number 19 got $\mathrm{V}$ rank with the mean score 13, design number 13 got VI rank by the 12.9 mean score, design number 17 got VII rank with the 12.8 mean score, design number 30 got VIII rank and its mean score 12.7, design number 20 got IX rank with the 12.5 mean score, design number 4 got $X$ rank with the 12.4 mean score.
In conclusion the guiding principle behind modest clothing among various religions and cultures is to wear clothing that projects a humbleness and humility about a person. ${ }^{6}$ Finding revealed that all the developed thirty designs of functional outfit having modesty features coupled with comfort, and convenience to make dressing and undressing easier for women were found highly appropriate in terms of unique functional attributes making them modest to wear in public. The developed designs can be used to implement the concept of modesty favorable to the women bath wear outfits.

\section{References}

1. http://adrielbooker.com/jessica-rey-themodesty-debate-and-bikini-burning

2. http://what-when-how.com/love-in-worldreligions/modesty-in-hinduism/

3. (https://www.drsunaina.com/blog/therelation-between-our-skin-and-secondskin/)

4. What Does Modest Fashion Really Look Like? Hannah Almassi, 23 February, 2018 
https://www.spireresearch.com/wpcontent/uploads/2019/07/Journal-Q2-2019Summer-issue_Fashion_Industry_ wakes_up_to_Modest-Wear.pdf

5. Shanu Parashar and Dr. Meenu Srivastava. 2019. Assessment of bathwear pattern of women and its associated problems at communal places. Int. J. Adv. Res. 7(11), 1013-1018.
6. Loch, B.J, 2011. What Is Considered To Be Modest Clothing? Article Dashboard: The web's premiere article directory. Retrieved on 18 June 2017 from http://www.articledashboard.com/Article/ What-is-Considered-to-be-ModestClothing/1389735

\section{How to cite this article:}

Shanu Parashar and Meenu Srivastava. 2020. Designing and Evaluation of Functional Modest Designs of Women Bath Wear. Int.J.Curr.Microbiol.App.Sci. 9(11): 2283-2289. doi: https://doi.org/10.20546/ijcmas.2020.911.273 